\title{
INTEGRATING DIVERSITY OF USERS' HUMAN FACTORS INTO A CORNERSTONe ENGINEERING DESIGN COURSE
}

\author{
Erica Attard, Michael A. Greig, W. Patrick Neumann, and Filippo A. Salustri \\ Ryerson University \\ Corresponding author: $\underline{\text { salustri@ ryerson.ca }}$
}

\begin{abstract}
The instructors of the undergraduate cornerstone design course in Mechanical and Industrial Engineering at Ryerson University aim to integrate diversity and inclusion into students' design education. Our goal is to provide resources that students can use to understand human capabilities and limitations, so their designs are better suited to a wide range of users. The project was broken down in four phases: Phase 1 consisted of scoping deliverables and background research; Phase 2 included courseware development; Phase 3 employed the courseware into the Fall 2019 offering of our cornerstone design course; and Phase 4 reviewed and analysed student's work to determine the efficacy of the courseware. To initiate this effort, we focused on three Human Factors: vision, hearing, and strength. We created a process whereby students could assess these Factors quantitatively for specific interactions and use the assessments to justify specific functional requirements and constraints of their own designs.
\end{abstract}

Keywords: Human Factors, Mechanical Engineering, Industrial Engineering, Engineering Design, Diversity, Inclusion.

\section{INTRODUCTION}

The instructors of the undergraduate cornerstone design course in Mechanical and Industrial Engineering at Ryerson University aim to increase the breadth and depth to which diversity and inclusion are integrated into students' design education. Students have difficulty finding reliable, usable human capability information resulting in weak designs that create unnecessary disabilities in users when the demands the design places on users exceed their individual capability. Our goal is to develop resources that students can easily use to understand human capabilities and limitations so that their designs will be better suited to a broader range of users.

MEC325 is the 3 rd semester cornerstone design course taken by all Mechanical and Industrial Engineering students that introduces students to designing and human factors (HF). A key component of the course is a semesterlong, team-based design project. Teams must submit a formal written report at the end of the semester on their design and how they developed it. The lectures and tutorials in the course explain the design process and provide oversight by TAs and instructors. The course is typically taught by Salustri and Neumann.

A key component of the project requires students to minimize the extent to which users will be excluded from using their products based on quantitative measures of various HFs such as vision, hearing, and strength.

In recent years, the teaching team has noticed that students tend to spend more time than expected looking for HF data and applying that information naively at best to their projects. In particular, we found that even if students found reasonable HF information, they rarely used it to address how their designs created disabilities by excluding users with capabilities that did not match the HF demands imposed by their designs.

Because of these problems, we decided to construct some tools and methods to help teams (a) find relevant HF data quickly and (b) use that data to assess user needs with the goal of minimizing the number of potential users excluded by virtue of HFs not matching users' capabilities.

Since the work reported herein fell under "Curriculum Development" and not research, no ethics review was required by Ryerson University.

\section{PROJECT DEVELOPMENT}

The project was implemented in four phases: Phase 1 involved scoping deliverables and conducting background research on available HF data and methods; in Phase 2, specific courseware was developed; Phase 3 saw the courseware deployed in the Fall 2019 offering of the course; and Phase 4 included an analysis of student work to determine the efficacy of the courseware. Each phase is described in detail below.

\subsection{Phase 1: Scoping \& Research}

In Phase 1 of our work, Attard conducted an extensive literature review. We discovered many sources of anthropometric data and general design guidelines for common design applications. However, very little information was available to help quantify HFs such as 
strength and perceptual ability and relating them to both specific products and types of interactions (e.g., pushing, lifting, etc.). This initiated a search to find empirically based data scales for each HF to quantify the HF demands inherent in a product.

We divided the HFs into three groups, perceptual (vision, hearing, taste, touch, smell, and balance), cognitive (memory, reasoning, and stress) and physical (strength, dexterity, mobility, and anthropometric data). The authors understand that social, political, economic, and cultural factors can influence how users engage with products, and thus influence the extent to which HFs "satisfy" user needs. However, these factors are currently beyond the scope of MEC325. While we recognize their importance of these other factors, we are constrained to set them aside.

For perceptual capabilities, scales such as the visual acuity scale and decibel scale are commonly used. However, scales for taste, touch, smell, and balance could not be found; these will be dealt with in future work. Cognition is extremely difficult to quantify for beginner designers due to its complex nature. For example,we considered the Mini-Mental State Exam (MMSE) and the Montreal Cognitive Assessment (MoCA) scales, but discarded because we could not relate them to product interactions as our students would be expected to use them. In contrast, there was ample physical strength data identified that was conveniently categorized according to task, age, and gender.

\subsection{Phase 2: Courseware Development}

In Phase 2 of the project, courseware was developed primarily by Attard to help students use the collected data sources to drive good design decisions. Our approach was to map HF data to population exclusion rates in four steps.

1. Each team would use HF data to determine the percentage of the general population excluded from using their reference design (i.e., an existing product that their design must "beat").

2. Each team would expand the range of inclusivity based on the strategic goals of their project. In essence, they would set new HF targets that would exclude fewer users than did their reference design.

3. Each team would reverse the calculations of the first step to determine the HF ranges that will include their new target users.

4. Each team would use those HF ranges to set requirements for their own design.

If teams do this work properly and design to the requirements they set, then they can be reasonably confident that, ceteris paribus, their design will be usable by more humans than the reference design.

Our first task was to specify how students could map $\mathrm{HF}$ data to population exclusion rates. For this, we used the University of Cambridge Exclusion Calculator [5] along with statistical data for various strength dependent tasks and the Liberty Mutual Manual Material Handling Tables
[5] [6]. Because of the ready availability of data, we focused on vision, hearing, and strength. We created a process, described below, that students could use to identify the most ergonomically onerous task for each HF in their reference design, then use the data to estimate the percentage of the general population excluded by the reference design. The process works both ways; that is, by reversing the steps, one could begin with a predetermined percentage of excluded users and determine the HF range a new design would have to meet to accommodate those users.

For other HFs (e.g., smell, balance, memory, etc.), we needed a single generic process that, though necessarily less accurate, would allow students to estimate the value ranges that could be used to drive design decisions. The students were asked to rate the severity, likelihood, and frequency of a task being performed on a simple threepoint scale.

Our second task was to determine where to inject the new material into the existing courseware, and what specifically had to be added.

The overall design process used in the course is available online as a "Design Roadmap". The process has four stages relevant to the work reported here: determine the current situation for which a designed intervention is needed; determine a set of engineering requirements that hold for any intervention that would improve the current situation sufficiently; develop a system architecture for the intervention; and finally develop a concept for the design.

In the first stage, teams must, among other things, determine a suitable reference design, develop several situated use cases for that design, and specify a typical flowchart-like usage scenario that captures the key tasks users must perform to use the reference design. For each $\mathrm{HF}$, teams then analyze the usage scenarios to find the tasks that will be most onerous for users. Based on that analysis, teams then determine the percentage of users excluded to establish the HF demands of the reference design. This is the first place where new courseware was needed.

In the second stage, each team must choose which HFs need to be adjusted to address unreasonable rates of user exclusion; that is, teams must consider the HF capabilities of their target users. This is the second place where new courseware was needed: students must convert the expanded inclusion ranges into expanded value ranges for each HF.

For instance, a team designing a new "way to blend food at home" may find from their use cases and usage scenario that the most onerous strength task is lowering the reference design blender from a high shelf down to a kitchen counter, especially for, say, elderly users. Using the weight of the reference design, and the courseware to be provided, a team might determine $20 \%$ of the general population cannot safely execute that task. The team may then decide, based on the scope and strategy of their project, that their new design should exclude no more than 
$10 \%$ of users. This lower exclusion rate must then be translated into a maximum weight that can be safely lifted. This new weight eventually becomes an engineering requirement for their new blender design.

Throughout the rest of the project, students are advised to refer back to their requirements and HF calculations to justify their decisions. We intentionally check the frequency of such justifications as well as their robustness as part of the grading of the final project reports.

\subsection{Phase 3: Deployment and Delivery}

The courseware was integrated by Salustri into a wiki at the end of Summer 2019 for deployment in the Fall 2019 offering of MEC325.

Lecture slides were revised to suit. Rubrics for the project's Milestones and Final reports were updated by Salustri and Neumann. Specific elements were added to the rubrics for $\mathrm{HF}$ demands and capabilities; rubric items treating the justifications for design decisions were updated to reference HFs directly. These rubric elements were weighted heavily to ensure that students understood that good design requires attending to the "human in the system". Since many students rely on information passed on to them from previous years' students via the internet, students were informed from the first day of class of the modifications.

No significant problems arose during deployment and delivery of the material.

\subsection{Phase 4: Analysis}

Phase 4, conducted in Winter 2020, examined whether and to what extent the interventions described above improved student understanding and use of HFs in design. Details of the analysis are provided in Section 3.3, below.

\section{COURSEWARE}

In this section, we present specifics of the tools and courseware developed.

The human factors on which we focused (vision, hearing, and strength) were analyzed using separate scales with similar procedures to maintain constancy and ensure the usability of the courseware. The procedure has three main steps: quantitatively identify the HF demands of a specific task performed with the reference design; compare the value to human factors data and scales to determine the human capability range included; and determine the percentage of population excluded from performing the specified task using additional resources provided.

\subsection{Background Research and Deliverables}

As explained above, sufficient useful information was only discovered for vision, hearing, and strength. These human factors became the focus of the new courseware.

The deliverables were as follows: identify a practical and usable quantifiable scale for each human factor; relate the scale to the reference design or tasks; and match each scale to the population. The scales used for vision, hearing, and strength are described below.

3.1.1. Vision. "Visual acuity" refers to a person's ability to see an object at a set distance with sharpness and clarity. Normal vision is expressed as 20/20, meaning an individual can see clearly at 20 feet what normally should be seen at 20 feet. Increasing the denominator indicates one must be closer to the object to view it clearly. A visual acuity of 20/120 indicates an individual must stand as close as 20 feet to clearly view an object that, with $20 / 20$ vision, can be seen clearly at 120 feet. Visual acuity does not consider eye coordination, colour vision, or depth perception, which all have a significant effect on one's ability to perceive an object [8]. Although this scale provides an accurate method for quantifying vision, visual acuity is not easily or directly measurable on a reference design. In order for students to determine the range of visual acuity required to complete a task, modifying factors including the font size, contrast level, quantity of white space, and glare level can be measured and compared to an everyday task associated with a specific range of visual capabilities. Other factors such as distance, lighting, space, color, and placement also affect visual acuity; however, we could not find a repeatable and easy measurement method suitable for use by our students [1].

3.1.2. Hearing. Hearing is used to operate many devices and is often required to communicate between a product and its user. If the user has hearing loss due to prolonged loud noise exposure or age, any design that uses sound creates an inherent disability. The loudness of sound is measured in decibels $(\mathrm{dB})$ and can be quantified using a sound meter [3]. The amount of hearing loss can be described by a scale indicating a range for normal hearing loss $(-10 \mathrm{~dB}$ to $25 \mathrm{~dB})$, mild hearing loss $(25 \mathrm{~dB}$ to $40 \mathrm{~dB})$, and moderate to severe hearing loss $(40 \mathrm{~dB}$ to $70 \mathrm{~dB})$, measured in decibels [2]. Since most teams will not have access to their reference design, everyday sounds were fitted to a decibel range so students can approximate the auditory requirements of their reference design using online sources and compare.

3.1.3. Strength. Physical strength is required in multiple tasks typically associated with product use, including lifting, pulling, pushing, gripping, grasping, carrying, twisting, and pressing. Each task demands strength in different muscles and areas of the body. Therefore, these tasks were evaluated separately. Tasks requiring high levels of force can lead to injury of the user. Population strength range data was collected for various tasks and sorted by age and gender.

\subsection{Courseware Methods}

In this section, we provide an overview of the specific methods deployed in the courseware. This courseware was 
produced by Attard and was implemented into the overall roadmap of the MEC325 design project.

The above information was sorted into an intuitive procedure for each human factor. The students were to follow the steps outlined, use the resources provided, and produce a chart that would collect all the information and present it in an organized fashion. The procedures for vision, hearing, and strength are described below.

3.2.1. Vision. The Visual Acuity Scale and the University of Cambridge Exclusion Calculator were combined to create an easy way of comparing an everyday task to a task that is required by the reference design [4]. Three tasks were listed with their corresponding modifying factors: reading a regular newspaper, reading a newspaper with large print, and reading a newspaper headline [5]. The modifying factors (font size, contract, white space, and glare) gave measurable quantities to the students to assist with their evaluation of the reference design. These values were then compared to the values in Table 1 (below) to determine which everyday task their selected task best correlates with. The associated visual acuity required to perform the task can be found from the table as well. The modifying factors and the corresponding visual acuity requirements can be seen in Table 1 .

Table 1: Everyday tasks for vision, their modifying factors, and visual acuity requirements [4] [5].

\begin{tabular}{|c|c|c|}
\hline $\begin{array}{c}\text { Everyday } \\
\text { Tasks }\end{array}$ & $\begin{array}{c}\text { Modifying } \\
\text { Factors } \\
\end{array}$ & $\begin{array}{c}\text { Visual Acuity } \\
\text { Range Included }\end{array}$ \\
\hline & $\begin{array}{l}\text { 12-16 size font } \\
\text { Low contrast } \\
\text { Low white } \\
\text { space } \\
\text { High glare }\end{array}$ & $\begin{array}{l}\text { Normal Vision, } \\
\text { Visually } \\
\text { Impaired } \\
20 / 20 \text { to } 20 / 60\end{array}$ \\
\hline Large Print & $\begin{array}{l}13-24 \text { size font } \\
\text { Some contrast } \\
\text { Some white } \\
\text { space } \\
\text { Some glare }\end{array}$ & $\begin{array}{l}\text { Normal Vision, } \\
\text { Visually } \\
\text { Impaired, and } \\
\text { Low Vision } \\
20 / 20 \text { to } 20 / 160\end{array}$ \\
\hline $\begin{array}{l}\text { Newspaper } \\
\text { Headline }\end{array}$ & $\begin{array}{l}28+\text { size font } \\
\text { High contrast } \\
\text { High white } \\
\text { space } \\
\text { Low glare }\end{array}$ & $\begin{array}{c}\text { Entire Range } \\
20 / 20 \text { to } 20 / 400\end{array}$ \\
\hline
\end{tabular}

The category chosen was then inputted into the University of Cambridge calculator to determine the percentage of the population that was excluded [5].

3.2.2. Hearing. The hearing loss scale was adapted from the University of Cambridge Exclusion Calculator allowing students to compare everyday tasks with an associated decibel range to an auditory task required by their reference design [5]. Students were to approximate the sound level in decibels for the auditory task selected and use Table 2 (below) to determine the hearing level requirements to perform the task.

Table 2: Everyday tasks for hearing, their modifying factors, and hearing level requirements [2] [5].

\begin{tabular}{|c|c|c|}
\hline $\begin{array}{c}\text { Everyday } \\
\text { Task }\end{array}$ & $\begin{array}{l}\text { Modifying } \\
\text { Factors }\end{array}$ & $\begin{array}{c}\text { Hearing Loss } \\
\text { Range Included }\end{array}$ \\
\hline $\begin{array}{l}\text { Background } \\
\text { Noise }\end{array}$ & $\begin{array}{l}\text { Follow } \\
\text { conversation } \\
\text { against } \\
\text { background } \\
\text { noise. } \\
35-40 \mathrm{~dB}\end{array}$ & $\begin{array}{c}\text { Normal } \\
\text { Hearing } \\
-10 \text { to } 25 \mathrm{~dB} \\
\text { loss. }\end{array}$ \\
\hline Telephone & $\begin{array}{l}\text { Use telephone } \\
\text { without special } \\
\text { adaptations for } \\
\text { hearing } \\
\text { impairment. } \\
50-70 \mathrm{~dB}\end{array}$ & $\begin{array}{l}\text { Normal and } \\
\text { Mild Hearing } \\
\text { Loss } \\
-10 \text { to } 40 \mathrm{~dB} \\
\text { loss. }\end{array}$ \\
\hline $\begin{array}{c}\text { Loud Speech } \\
\text { in a Quiet } \\
\text { Room }\end{array}$ & $\begin{array}{l}\text { Understand } \\
\text { loud speech in a } \\
\text { quiet room. } \\
90 \mathrm{~dB}\end{array}$ & $\begin{array}{l}\text { Entire Range } \\
-10 \text { to } 70 \mathrm{~dB} \\
\text { loss. }\end{array}$ \\
\hline
\end{tabular}

Once the reference everyday task was identified, the students were to input the information into the University of Cambridge Exclusion Calculator to determine the percentage of population excluded from performing this task [5].

3.2.3. Strength. Given the variety of strength tasks, three methods were developed to determine the strength requirements of the reference design based on the task and weight of the object. Method 1 was designed for lifting an object less than $2.5 \mathrm{~kg}$ in mass. Students were to approximate the weight of their reference design and compare it to the everyday tasks outlined in Table 3 below. From this table, the student can then determine the percentage of the population excluded from performing the task.

Table 3: Method 1: For everyday strength tasks for objects under $2.5 \mathrm{~kg}$ [5].

\begin{tabular}{|c|l|c|}
\hline \multicolumn{1}{|c|}{$\begin{array}{c}\text { Everyday } \\
\text { Task }\end{array}$} & Modifying Factors & $\begin{array}{c}\text { Population } \\
\text { Excluded }\end{array}$ \\
\hline Mug & $\begin{array}{l}\text { Pick up and hold a } \\
\text { mug of coffee by the } \\
\text { handle. } \\
0.001 \mathrm{~kg} \text { to } 0.765 \mathrm{~kg}\end{array}$ & $1.1 \%$ \\
\hline & $\begin{array}{l}\text { Pick up and carry a } \\
\text { bottle of wine or } \\
\text { glass bottle of milk } \\
\text { without } \\
\text { condensation. }\end{array}$ & $2.4 \%$ \\
\hline
\end{tabular}




\begin{tabular}{|l|l|l|}
\hline & $0.766 \mathrm{~kg}$ to $1.95 \mathrm{~kg}$. & \\
\hline $2.5 \mathrm{~kg}$ & $\begin{array}{l}\text { Pick up and carry a } \\
\text { plastic shopping bag } \\
\text { containing four pints } \\
\text { of milk. } \\
1.96 \mathrm{~kg} \text { to } 2.5 \mathrm{~kg} .\end{array}$ & \\
\hline Shopping Bag & \\
\hline
\end{tabular}

Method 2 was employed for lifting, pushing, pulling, lowering, and carrying an object with a mass greater than $2.5 \mathrm{~kg}$. The object weight and task specifications were inputted into the Liberty Mutual Material Handling Tables and the percentage of population excluded from performing the task was documented [6].

Method 3 was used for more detailed tasks including twisting, opening, pushing with a finger, pressing with a foot, etc. Strength requirements for objects with a mass greater than $2.5 \mathrm{~kg}$ were evaluated using Strength Data for Design Safety from Nottingham University [8]. Students were to approximate the force required to perform the task via measurement or online research. An age range was then selected based on the target audience for the reference design and the data was presented in terms of percentile of the general population included as potential product users. The students compared their force requirement with a table to determine which percentile could complete the task.

3.2.4. Other Human Factors. We were unable to develop methods for the other HFs mentioned in Section 2. For the other perceptual, cognitive, and physical HFs, a generic method was developed by Salustri and Neumann to "fill in the blanks" until such time as we can develop better methods. This generic method required students to assess subjectively the percentage of users excluded from using a product. However, all such decisions had to be justified and explained thoroughly by each team.

\subsection{Analysis}

In this section, we report on analyses done to try to assess the success of our interventions based on the quality of the design elements generated by the students.

The design project reports were all graded by Salustri according to a standardized rubric that had been made available to students. After final grades had been submitted, Greig undertook the analysis of the grades.

The grades breakdown of the design projects $(n=60)$ was reviewed to detect changes in design outcomes that could be attributed to our interventions. Components of the report rubric were deconstructed, and specific rubric elements were isolated to see if the HF Capabilities component of the rubric correlated with improved design elements evolving later in the project - i.e., Personas, the final Product Concept, Detailed Design, and the resulting CAD models. Each element was assigned a specific grade component by Salustri. Since Salustri was unaware of the nature of Greig's analyses when he graded the reports, we are confident that no biases were introduced during grading due to foreknowledge of subsequent analytic work.

HF Capabilities and Personas were scored on an integer 0 to 4 scale, consistent with the rubric's grading scale. However, the Product Concept, Detailed Design, and CAD components had whole sections in the rubric, and were sums of weighted components, resulting in continuous values between 0 and 4 . The average and standard deviations of the five items are shown in Table 4.

Table 4. Averages, standard deviations, and Pearson correlations of the four items used for comparison in the 60 design projects with respect to HF Capabilities.

\begin{tabular}{|l|c|c|c|}
\hline $\begin{array}{c}\text { Comparison } \\
\text { Element }\end{array}$ & Avg. & Std. Dev. & $\mathrm{R}$ \\
\hline $\begin{array}{l}\text { Human Factors } \\
\text { Capabilities }\end{array}$ & 1.75 & 0.77 & \\
\hline Personas & 1.98 & 0.54 & 0.0307 \\
\hline $\begin{array}{l}\text { Product Concept } \\
\text { Specification } \\
\text { (PCSg) }\end{array}$ & 2.39 & 0.25 & -0.0458 \\
\hline Detailed Design & 1.84 & 0.59 & 0.1149 \\
\hline CAD & 2.36 & 0.74 & 0.0263 \\
\hline
\end{tabular}

Pearson's product-moment correlation (R), identifies correlations between the two sets of data, was calculated for the HF Capabilities scores versus the scores of the other items, as shown in Table 4. In our case, we compared the HF Capabilities to each of the other items described above. Detailed design showed the highest correlation with HF Capabilities, but could be considered marginal at best. These relationships are shown graphically for the correlation between HF Capabilities and the Personas (Fig. 1), Product Concept (labelled PCSg) (Fig. 2), Detailed Design (Fig. 3), and CAD (Fig. 4). Figures 1-4 show the variability in the relationships between the two variables in comparison and confirms the lack of substantial correlation in the summary of information in Table 4.

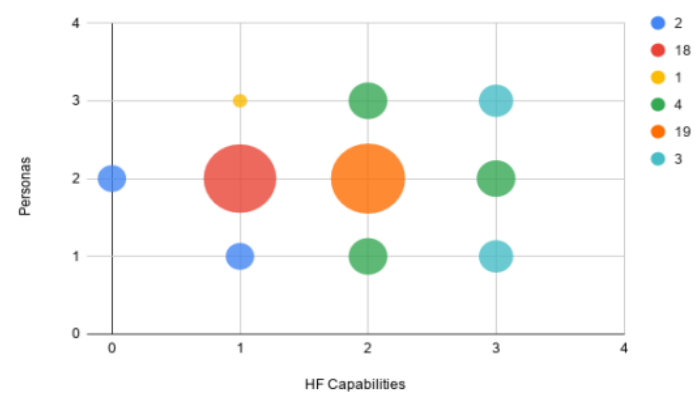

Fig. 1. Relationship between variable scores given in the design projects for HF Capabilities and Personas, where the bubble size and colour indicate the count of occurrences in the combination. 


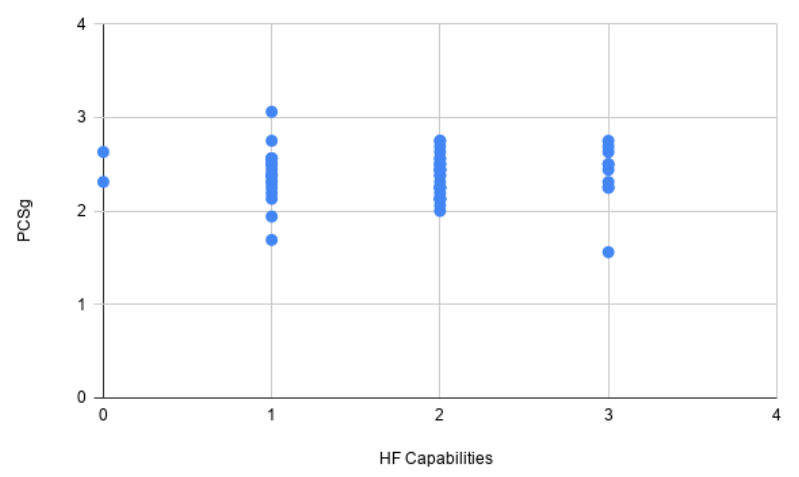

Fig. 2. Relationship between the scores given in the design projects for HF Capabilities and Concept Generation (labelled PCSg).

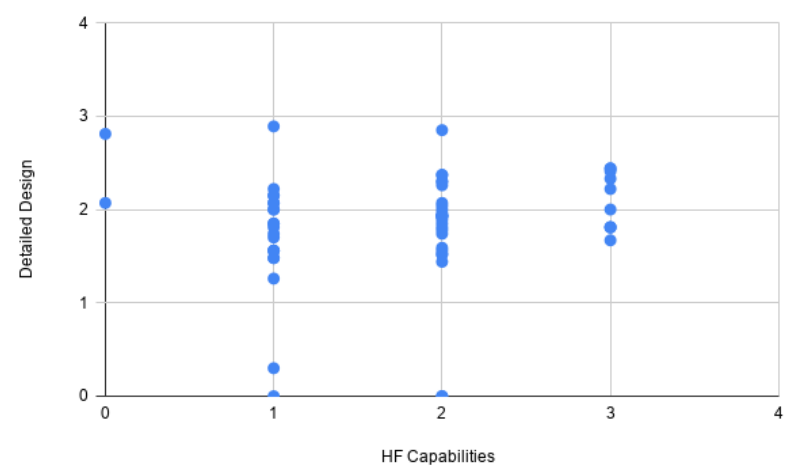

Fig. 3. Relationship between the scores given in the design projects for HF Capabilities and Detailed Design.

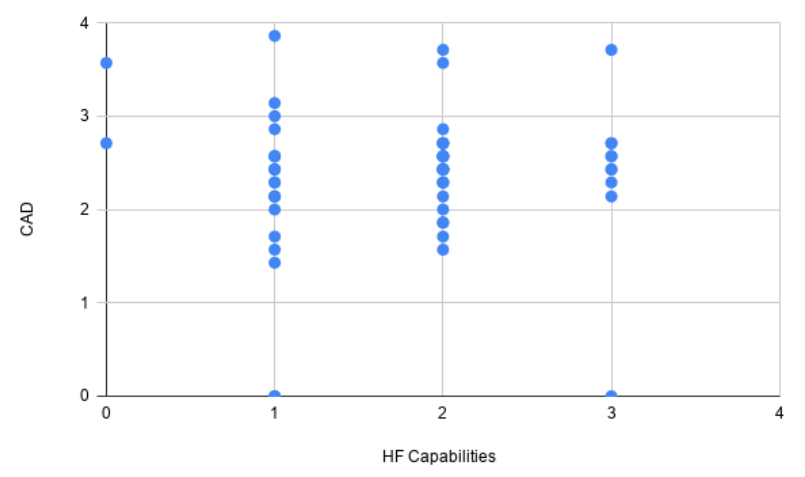

Fig. 4. Relationship between the scores given in the design projects for HF Capabilities and CAD.

\section{DISCUSSION}

\subsection{Challenges in Development and Deployment}

The authors encountered several challenges during development and deployment of the new courseware.

4.1.1. The ubiquity of HF. HF can impact virtually every aspect of product engineering in many different ways. This made it difficult to (a) isolate HF aspects that could be described in teachable "modules" and (b) develop meaningful assessments of student work that isolate this new learning. Our approach is to consider each HF separately at various stages of our design process; the shortcoming is that we lose the coupling that exists between different HFs.

4.1.2. Lack of scales for some HFs. We could not find scales for measuring human capabilities for taste, touch, smell, and balance. We thus had to resort to more subjective methods for students to assess those capabilities. This made it impossible to teach students how they can design for others with respect to those HFs with the kind of certainty that can be achieved for HFs like vision or hearing, as well as relating those HFs to specific product interactions that students might have identified as problematic. It is also very difficult to assess those more subjective assessments.

4.1.3. Disconnect between HFs and design components. We found it difficult to provide sufficiently comprehensive yet accessible HF tools to handle all aspects of a product's design for an introductory design course. For instance, the standard vision scales work well for distance, but did not apply to design issues like contrast, level of object detail, etc. As a result, students' assessments of designs were partial at best. We have currently no reasonable ideas of how this can be addressed without significant further research in HF.

\subsection{Challenges in Analysis}

Establishing a robust and reliable approach to connect the impact of the change in HF resources and tools to the quality of the design project is a challenging operation to complete, especially after grading is already completed. The use of a different grading strategy in future iterations of the course compared to the one used for these projects may help isolate the effects of these pedagogical changes, although this evaluation issue alone warrants further investigation. A challenge within the existing data is to know if an HF Capabilities score that is less than or equivalent to the other scores is an actual indication of improved application and, similarly, if a higher HF Capabilities score in comparison shows good uptake of HF information and poor transfer of knowledge to the design elements. Manipulation of the data to reflect these different concepts was inconclusive and was not trustworthy enough to make any commentary of significance aside from the challenge in interpretation. Another methodological challenge is the perpetual question of the reliability of the grading done during the semester, which was done under tight time and resource constraints. While isolating the impacts of adding HF into design education is a non-trivial problem, the inability to quantify these does not prove that no beneficial learning by students occurs. Our current evaluation strategy lacks 
sensitivity and specificity to detect the effects that the inclusion of $\mathrm{HF}$ aspects in design teaching may be causing. In this case, qualitative methods, such as interviewing students, could yield some useful feedback.

Due to evolving course content and associated changes in grading rubrics, a year-over-year comparison was also not possible. Likewise, a within class case-control comparison is not possible due to the structure of the class - the course is broken down into sections for labs but runs with a common lecture. The ethics of experimentation on the class in real-time is also a questionable practice. The most feasible approach is a multi-year review plan. Any continuous improvement plans for the course would have to be tempered or finely controlled to ensure consistency in comparison and minimize the impact of other variables. There is, we note, a tension between the time and resources available to develop and implement course improvements, and the resources needed to conduct a scientifically satisfactory evaluation of these efforts. Ideally, the reports would be assessed separately and by a disinterested third party to help ensure objectivity. A dedicated researcher would be needed over the same time period as well to maintain consistency. There is currently no funding to reach this goal.

\section{CONCLUSION}

This paper has presented a "narrative" account of the authors' attempts to improve the effectiveness and efficiency of students' use of HF data in a cornerstone engineering design course. The problem the authors faced was that students were spending too much time searching for and trying to understand $\mathrm{HF}$ information, and not enough time using that information to improve their designs. Sources of information were cataloged for students. Specific tools and methods were developed and deployed. The results were analyzed, with relatively ambiguous results.

If we accept the results at face value, then the introduction of the new material made no statistically significant impact. However, several factors outlined above may have influenced the results and been conflated with the effect of the specific interventions described in this paper. Better evaluation approaches are needed.
In the future, we will devise an alternative method likely involving separate assessment of projects. We will present those results at a future CEEA conference.

\section{Acknowledgements}

The authors acknowledge the financial support of Ryerson University's Centre for Excellence in Learning and Teaching via a Learning and Teaching Grant. No ethical review was required as the work presented here was categorized as "curriculum development", not "research".

\section{References}

[1] E., Kroemer K H. Fitting the Task to the Human: Introduction to Ergonomics. CRC Press, 2009.

[2] D. Clason, "Degrees of Hearing Loss and Hearing Loss Levels," Healthy Hearing, 24-Feb-2020. [Online]. Available: www.healthyhearing.com/report/41775Degrees-of-hearing-loss.

[3] "Hearing Loss," Mayo Clinic, Mayo Foundation for Medical Education and Research, 10-May-2019. [Online]. Available: www.mayoclinic.org/diseasesconditions/hearing-loss/syptoms-causes/syc20373072.

[4] International Council of Ophthalmology (1988). Visual Acuity Measurement Standard. Published in the Italian Journal of Ophthalmology II.

[5] Joy Goodman-Deane, Sam Waller, Elaine Williams, Pat Langdon, and John Clarkson. Estimating exclusion: a tool to help designers. IN: Proceedings of Include 2011, Royal College of Art, 18-20 April 2011.

[6] Snook, S.H., Cirello, V.M., The Design of Manual Handling Tasks: Revised Tables of Maximum Acceptable Weights and Forces. Ergonomics 34, 1197 $1213,1991$.

[7] "Strength Data for Design Safety Phase 1." University of Nottingham, Department of Trade and Industry, Product Safety and Testing Group, Oct-2000, https://webarchive.nationalarchives.gov.uk/+/http:/ww w.dti.gov.uk/files/file21830.pdf

[8] "Visual Acuity." American Optometric Association. [Online]. Available: https://www.aoa.org/healthyeyes/vision-and-vision-correction/visual-acuity?sso=y. 